\title{
O FOMENTO FLORESTAL COMO ALTERNATIVA DE SUPRIMENTO DE MATÉRIA-PRIMA NA INDÚSTRIA BRASILEIRA DE CELULOSE
}

\author{
Augusto Fischer \\ augusto_fischer@twc.com.br \\ Universidade do Oeste de Santa Catarina - Joaçaba, SC / Brasil \\ Décio Zylbersztajn \\ dezylber@usp.br \\ Universidade de São Paulo - São Paulo, SP / Brasil
}

Recebido em 10/02/2010

Aprovado em 16/03/2012

Disponibilizado em 01/08/2012

Avaliado pelo sistema double blind review

Revista Eletrônica de Administração

Editor: Luís Felipe Nascimento

ISSN 1413-2311 (versão on-line)

Editada pela Escola de Administração da Universidade Federal do Rio Grande do Sul.

Periodicidade: Quadrimestral

Sistema requerido: Adobe Acrobat Reader.

\section{RESUMO}

Neste estudo foram analisados os programas de fomento florestal das empresas do segmento de celulose. O objetivo é identificar a participação do fomento florestal no suprimento de madeira e as dimensões definidas nos contratos desses programas. Para o estudo utilizou-se o referencial teórico da nova economia institucional, particularmente a teoria dos contratos incompletos de longo prazo e dos custos de transação. Utilizou-se a abordagem qualitativa da pesquisa exploratória e descritiva. Para isso, após estudo documental sobre o ambiente regulatório e institucional do setor florestal, realizou-se a coleta de dados primários por meio de questionário semiestruturado, encaminhado por meio eletrônico a dirigentes e técnicos de onze empresas produtoras de celulose escolhidas intencionalmente. Os resultados mostram que o fomento florestal ocupa a segunda posição na matriz de suprimento de madeira para processamento da indústria de celulose como mecanismo de substituição da integração vertical, pela coordenação vertical por meio de contratos de longo prazo. Indicam, também, que a participação dos programas de fomento florestal e do mercado no suprimento de madeira para processamento está crescendo. O fomento visa a facilitar o acesso a recursos, associados ao cultivo florestal, reduzindo os custos associados à imobilização em terras, fomentando o aumento da oferta de madeira para processamento. As empresas estruturam modalidades diferentes dos programas de fomento para adequar os incentivos aos produtores de acordo com o porte de suas propriedades. Excetuando-se o fomento de extensão, os demais programas de fomento usam a opção de compra da produção.

Palavras-chave: Economia florestal, estrutura de incentivos, contratos, economia dos custos de transação.

THE FOREST FURTHERANCE: AN ALTERNATIVE OF RAW MATERIAL IN BRASILIAN PULP INDUSTRY

REAd I Porto Alegre - Edição 72 - N 2 - maio/agosto 2012 - p. 494-520 


\begin{abstract}
This work studied the programs of forest furtherance developed by companies in the pulp segment. The objective is to identify the participation of forest furtherance in wood supply and dimensions defined in contracts of these programs. The study used the theoretical framework of new institutional economics, with emphasis in theory of long term incomplete contracts and transaction costs. Qualitative approach in the exploratory and descriptive study of multiple cases was used. After a documental study on the regulatory and institutional environment of forest sector, there was collected primary data through semi-structured questionnaire, sent electronically to managers and technicians of eleven pulp production companies intentionally chosen. The results show that forest furtherance occupies the second position in the supply matrix of timber for pulp processing industry, whose participation tends to increase with the trend of replacing the vertical integration by vertical coordination through long-term contracts. The results also show that the participation of programs to forest furtherance and market in the timber supply for processing is growing. The furtherance aims to facilitate efficient access and availability of land suitable for forestry cultivation, reducing the costs associated with detention of land and increasing the timber supply for processing. The companies structure different modalities of furtherance programs, to attend to different classes of encouraged producers, mainly pursuant to the size of their farms. Except the extension furtherance, the other programs of forest furtherance use option to purchase option of output.
\end{abstract}

Keywords: Forest economics, structure of incentives, contracts, transaction costs.

\title{
1 INTRODUÇÃO
}

A indústria florestal brasileira tem importância econômica e social, sendo considerada a mais expressiva da América Latina (ABIMCI, 2001). O setor de base florestal madeireira tem significativa participação na formação do PIB nacional, na geração de tributos e nas exportações, com destacada contribuição na formação de superávit na balança comercial, além da expressiva geração de empregos diretos e indiretos (ABIMCI, 2003a). Somando-se aos aspectos já mencionados, também pode proporcionar benefícios ambientais, se planejado e manejado adequadamente, reunindo, então, atributos necessários ao desenvolvimento sustentável.

O referido setor compreende um conjunto de atividades primárias e secundárias. As atividades primárias constituem-se na extração vegetal, compreendendo a colheita dos produtos in natura e o manejo sustentado das florestas, e na silvicultura, compreendendo os manejos de florestas nativas e reflorestamentos. As atividades secundárias compreendem o beneficiamento e processamento subdividido nos segmentos de produtos derivados de madeira (madeira sólida, painéis reconstituídos, celulose e papel, móveis, lenha, carvão vegetal, resíduos de madeira que são utilizados como insumos para produção de energia e 
O fomento florestal como alternativa de suprimento de matéria-prima na indústria brasileira de celulose

outros produtos reconstituídos) e outros produtos de origem vegetal (erva-mate, resinas, óleos, fibras, essências, entre outros).

A silvicultura é a base predominante do setor florestal; as florestas plantadas são responsáveis por $100 \%$ do suprimento de madeira para a indústria nacional de celulose e de painéis reconstituídos, e por $70 \%$ da matéria-prima para a indústria de compensados. Como razões para este fato, apontam-se as várias restrições à exploração das florestas naturais que abriram espaço para o desenvolvimento da silvicultura madeireira destinada ao suprimento de matéria-prima de destacados segmentos industriais. A silvicultura brasileira para produção de madeira apresenta indiscutível crescimento, ao lado do seu considerável desenvolvimento tecnológico em que é referência internacional (BACHA; ANTONANGELO, 1997; URURAHY, 2003), e vem tomando gradativamente, o espaço da extração florestal, com vantagens econômicas, sociais e ambientais sobre aquela atividade. Os principais gêneros florestais cultivados pela silvicultura brasileira são eucaliptos e pínus. Os outros gêneros aparecem em menor escala.

Com base na economia dos custos de transação, segundo Williamson (1991b), as firmas podem se organizar de três formas - mercado, hierarquias ou híbridas —, que, interativamente, definem diferentes ambientes institucionais, os quais, por sua vez, interagem reversivamente com essas firmas. As instituições de governança — representadas por contratos interfirmas, corporações, bureaus, entre outras formas — são sustentadas pelo ambiente institucional, onde se situam os indivíduos.

Assim, dadas as restrições e estruturas de incentivo, impostas pelo ambiente institucional brasileiro, para as empresas industriais do setor florestal que dependem da silvicultura como fonte de matéria-prima, particularmente empresas de médio e grande porte, é comum o desenvolvimento de arranjos organizacionais que buscam, ou coordenação hierárquica (notadamente, a verticalização a montante da cadeia), como fonte de suprimento, ou a coordenação híbrida, por meio de parcerias com proprietários de terras, para o cultivo de florestas. Este arranjo é mais utilizado pelas empresas dos segmentos de celulose, painéis reconstituídos (aglomerados, placas de fibra de madeira de média densidade, chapas de fibra, painéis de partículas orientadas), e painéis de madeira sólida (compensados). Em proporções menos frequentes, as empresas dos segmentos de serrados e de móveis contam com florestas próprias (coordenação hierárquica a montante), mas, em geral, dependem de madeira fornecida pelo mercado. 


\section{Augusto Fischer \& Décio Zylbersztajn}

A integração das plantações de florestas na cadeia produtiva tem sua fundamentação na reposição florestal obrigatória estabelecida pelo Código Florestal Brasileiro (Lei 4.771, de 15 de setembro de 1965) (BRASIL, 1965). Essa estratégia, no entanto, incorre em elevados custos do capital imobilizado em terras, sobretudo, diante de limitações impostas pela legislação ambiental quanto à sua utilização. Além disso, gera impactos sociais negativos. A produção independente de madeira para fins comerciais, entretanto, não tem se desenvolvido suficientemente para atender à demanda crescente.

Além da integração vertical a montante das fontes de suprimento, com plantações próprias das florestas de eucaliptos e pínus, a indústria de base florestal compra madeira bruta no mercado e desenvolve diferentes arranjos contratuais de longo prazo. Entre eles destacamse os contratos de arrendamento de terras para plantios próprios e a formação de parcerias contratuais com proprietários de terras a fim de cultivarem florestas, e os programas de fomento florestal. Os programas de fomento florestal iniciados por algumas empresas na década de 1970 vêm recebendo atenção maior a partir da segunda metade da década de 1990.

O crescente interesse pelo fomento florestal como estratégia para a ampliação das áreas de cultivo florestal, ante as dificuldades de expansão da oferta de madeira bruta por meio das estratégias tradicionais (integração vertical, mercado, e contratos de longo prazo), e a disponibilidade de poucos estudos relacionados ao fomento florestal, foram os motivos que levaram a desenvolver o presente trabalho. O fomento florestal caracteriza-se como arranjo de coordenação vertical a montante, mediante integração de pequenas e médias propriedades rurais na produção de madeira para suprimento industrial, e baseia-se em mecanismos de incentivo à produção de madeira por meio de contratos de longo prazo com proprietários rurais. A integração das pequenas e médias propriedades rurais para ampliação da base florestal é medida indicada praticamente por todos os atores envolvidos nas discussões de soluções para a escassez de matéria-prima da indústria de base florestal. Optou-se por estudar os programas de fomento florestal do segmento de celulose, em razão desse segmento ter conhecimento acumulado pelas empresas em projetos desta natureza, cuja experiência pode contribuir no desenvolvimento do estudo. Várias empresas do segmento de celulose e papel, particularmente as maiores desse segmento, já desenvolvem programas de fomento florestal desde a década de 1970, para complementarem o suprimento de madeira.

No presente artigo analisa-se o fomento florestal desenvolvido pelas empresas produtoras de celulose, buscando as definições legais e as formas de sua aplicação pelas empresas, tendo por base a teoria institucional. O objetivo consiste em identificar a REAd I Porto Alegre - Edição 72 - N 2 - maio/agosto 2012 - p. 494-520 
O fomento florestal como alternativa de suprimento de matéria-prima na indústria brasileira de celulose

participação dos programas de fomento florestal no suprimento de madeira às indústrias de celulose, e identificar as dimensões que são definidas nos contratos desses programas. Objetiva-se identificar as condições da base de suprimento de madeira e sua relação com os programas de fomento, além do papel e das características dos referidos programas.

Para facilitar a exposição, dividiu-se o artigo em seis seções. Em seguida a esta introdução a segunda parte faz uma resenha sobre a silvicultura para a produção de madeira. A terceira seção apresenta um resumo dos arranjos alternativos para a produção de madeira; na quarta seção apresenta-se a metodologia, na quinta apresentam-se os resultados do estudo, destacando-se as modalidades de fomento utilizadas pelas empresas, e descrevem-se os incentivos e as salvaguardas contratuais desses programas, para, na sexta, tratar das considerações finais.

\section{A SILVICULTURA PARA PRODUÇÃO DE MADEIRA}

A importância econômica das florestas para fins industriais e energéticos é irrefutável. A Organização das Nações Unidas para Alimentação e Agricultura (FAO, 1997 apud ANDREWS, 2002), avaliou o mercado global de madeira e de produtos derivados da madeira em mais de 140 bilhões de dólares americanos, com perspectivas de crescimento contínuo. $\mathrm{O}$ valor global de importações em 2001 alcançou a cifra de 141,1 bilhões de dólares americanos (FAO, 2004).

Em 2001, as florestas plantadas eram de 187,1 milhões de hectares, correspondendo a 4,8\% do total de florestas (FAO, 2003). Nos últimos anos, as plantações de florestas apresentam um expressivo aumento, cuja média global de novas plantações é de 4,5 milhões de hectares anuais, sendo 3 milhões de hectares de florestas produtivas (FAO, 2001). Metade das plantações florestais tem como destino o uso industrial, $25 \%$ destinam-se aos fins não industriais e $25 \%$ não possuem especificação de aplicação. As florestas plantadas respondiam, naquele ano, por somente 5\% da cobertura global de florestas, sendo responsáveis pelo suprimento de $35 \%$ da demanda global de madeira bruta, devendo aumentar para $44 \%$ até o ano de 2020. Em alguns países as florestas plantadas já representam a principal fonte de suprimento de madeira industrial (FAO, 2001).

No Brasil, a indústria de base florestal vem aumentando sua dependência da silvicultura para suprimento de matéria-prima, substituindo gradativamente as florestas nativas. Essa iniciativa está relacionada às limitações naturais e técnicas, às restrições institucionais na utilização das florestas nativas para esses fins e às pressões de correntes REAd I Porto Alegre - Edição 72 - Nº 2 - maio/agosto 2012 - p. 494-520 


\section{Augusto Fischer \& Décio Zylbersztajn}

ambientalistas em prol da preservação das florestas naturais. As limitações propiciaram a implantação no Brasil da silvicultura intensiva moderna, com cultivo de florestas de espécies exóticas para substituição da madeira de florestas de difícil reposição (RODÉS, 1996), alcançando altas produtividades.

Enquanto na média mundial as florestas plantadas representam 4,8\% dos recursos florestais e são responsáveis por $30 \%$ do consumo de madeira, no Brasil, as florestas plantadas representam $0,9 \%$ dos recursos florestais e respondem por mais de $61 \%$ do consumo de madeira pela indústria (LEITE, 2003a). A participação da silvicultura no suprimento da indústria de base florestal madeireira somente é superada pelas florestas nativas nos segmentos de lenha industrial e de serrados. Os segmentos de celulose e de painéis reconstituídos (aglomerados, chapas de fibras e MDF) são abastecidos somente com madeira de florestas plantadas, o que determina a concentração espacial de suas instalações industriais nas regiões Sul e Sudeste do país.

A importância econômica da silvicultura na produção florestal brasileira está consolidada e tende a crescer ainda mais. Dados do IBGE relativos à produção florestal em 2003 registraram aumento de 44,6\%, passando do valor de $\mathrm{R} \$ 5,967$ bilhões para $\mathrm{R} \$ 8,627$ bilhões. A participação da silvicultura na produção florestal aumentou de 52\% em 2002 para 65\% em 2003, o que representa um crescimento de 80,7\% (IBGE, 2003). Dados da pesquisa Produção de Extração Vegetal e da Silvicultura (PEVS), relativos a 2007, apontam que a produção primária do setor florestal somou $\mathrm{R} \$ 12,1$ bilhões, sendo $\mathrm{R} \$ 8,3$ bilhões $(68,7 \%)$ provenientes da silvicultura, e R $\$ 3,8$ bilhões (31,3\%) do extrativismo (IBGE, 2007). O setor florestal e sua cadeia produtiva representam 4,5\% do PIB do país e emprega aproximadamente 6,5 milhões de pessoas, correspondendo a 9,5\% da população economicamente ativa (ABIMCI, 2003b).

O desenvolvimento da silvicultura para a indústria brasileira do setor de base florestal, particularmente de celulose e madeira sólida, teve grande avanço a partir das décadas de 1970 e 1980, virtude atribuída principalmente à política de incentivos fiscais para reflorestamento, instituída a partir do $2^{\circ}$ Código Florestal promulgado em 1965, e que vigorou até 1986.

Viana et al (2002) destacam três fases para as plantações florestais no Brasil. Durante a primeira fase, anterior a 1965, predominaram as plantações florestais financiadas por companhias ferroviárias e outras empresas estatais consumidoras de lenha ou carvão vegetal para energia. A segunda fase, compreendida no período de 1965 a 1988, foi marcada pelos programas de incentivos fiscais decretados pelo governo federal. A terceira fase, a partir de REAd I Porto Alegre - Edição 72 - N 2 - maio/agosto 2012 - p. 494-520 
O fomento florestal como alternativa de suprimento de matéria-prima na indústria brasileira de celulose

1988, caracteriza-se pela eliminação dos incentivos fiscais para o reflorestamento em nível federal, mantendo-se alguns programas em nível estadual; esta é a fase atual.

Apesar da produtividade das florestas plantadas se situar entre as mais altas do mundo (BACHA; ANTONANGELO, 1997; URURAHY, 2003), o país passava desde 2000 por dificuldades no suprimento de madeira industrial, principalmente de Pínus, sendo o momento conhecido como "apagão florestal." A produtividade das espécies do gênero Eucalipto (principalmente Eucaliptus saligna e Eucaliptus grandis), e do gênero Pínus (principalmente Pinus elliottii e Pinus taeda) - os gêneros mais cultivados pela silvicultura brasileira cresceu no período de 1968 a $1995,163 \%$ e 68,5\% respectivamente (BACHA; ANTONANGELO, 1997). Atualmente já se registram níveis de equilíbrio entre demanda e oferta de madeira bruta em toras, devido ao desaquecimento da demanda industrial florestal, principalmente dos segmentos de serrados, produtos de maior valor agregado e móveis.

Tuoto (2003) e Leite (2003a) adiantavam que as dificuldades de atendimento às demandas deveriam durar até 2009. A demanda de madeira em toras tem sido maior que a capacidade da produção sustentada dos florestamentos e reflorestamentos existentes, sobretudo pelo fato dos novos empreendimentos terem ficado aquém das necessidades. $\mathrm{O}$ desequilíbrio de oferta deverá ser maior nas regiões Sul e Sudeste e para os segmentos de serrados, laminação e móveis. Segundo Leite (2003b), mesmo para setores que somente têm condições de existir com o uso de matéria-prima plantada e uniforme, como no caso da indústria de celulose e papel, que já possuem uma política florestal mais organizada proporcionando-lhes maior segurança, haverá necessidade de se ampliar a base florestal atual para atender a novas demandas previstas.

Todavia, com base em avaliações feitas por Tomaselli e Siqueira (2004), os riscos do descompasso entre oferta e demanda, atenuariam durante os próximos anos. Para os referidos autores, o desequilíbrio foi, até certo ponto, um exagero. Isto se confirmaria mais tarde, pois, a partir de 2007, a valorização cambial, principalmente do real frente ao dólar americano, reduziu as pressões sobre a oferta em razão da desaceleração do ritmo das exportações de produtos de madeira sólida, como serrados, produtos de maior valor agregado, compensados e móveis.

Por outro lado, o problema de oferta não é maior graças aos esforços do setor privado com o apoio de universidades e centros de pesquisas, na busca de aumento da competitividade. Segundo a Sociedade Brasileira de Silvicultura - SBS, a área estimada de florestas plantadas por volta do ano de 1987 era de, aproximadamente, cinco milhões de REAd I Porto Alegre - Edição 72 - N 2 - maio/agosto 2012 - p. 494-520 
Augusto Fischer \& Décio Zylbersztajn

hectares entre eucalipto e pínus. Em 2006, a área plantada era de 5,7 milhões de hectares, principalmente de eucaliptos e pínus (SBS, 2007, p. 43). A principal explicação para a manutenção da capacidade de suprimento de madeira até agora, sem maior expansão das áreas plantadas, é que empresas do setor investiram pesadamente em ciência e tecnologia, por intermédio das universidades e centros de pesquisa, obtendo salto espetacular na produtividade florestal.

\section{OS ARRANJOS ALTERNATIVOS PARA PRODUÇÃO DE MADEIRA}

Para atender a sua demanda de madeira em toras as empresas da indústria florestal podem desenvolver diferentes alternativas de arranjos organizacionais, demonstradas na Figura 1. Baseado em Williamson $(1985,1996)$, estes arranjos podem ser caracterizados como segue:

a) Integração vertical dos florestamentos e reflorestamentos;

b) Compra de madeira em toras no mercado spot, de produtores independentes ou excedentes de madeira em toras de empresas do setor florestal;

c) Arranjos contratuais híbridos por meio de contratos de longo prazo, que podem ser divididos em: arrendamento de terras, parceria florestal e fomento florestal.

Figura 1 - Alternativas para suprimento de madeira na indústria base florestal

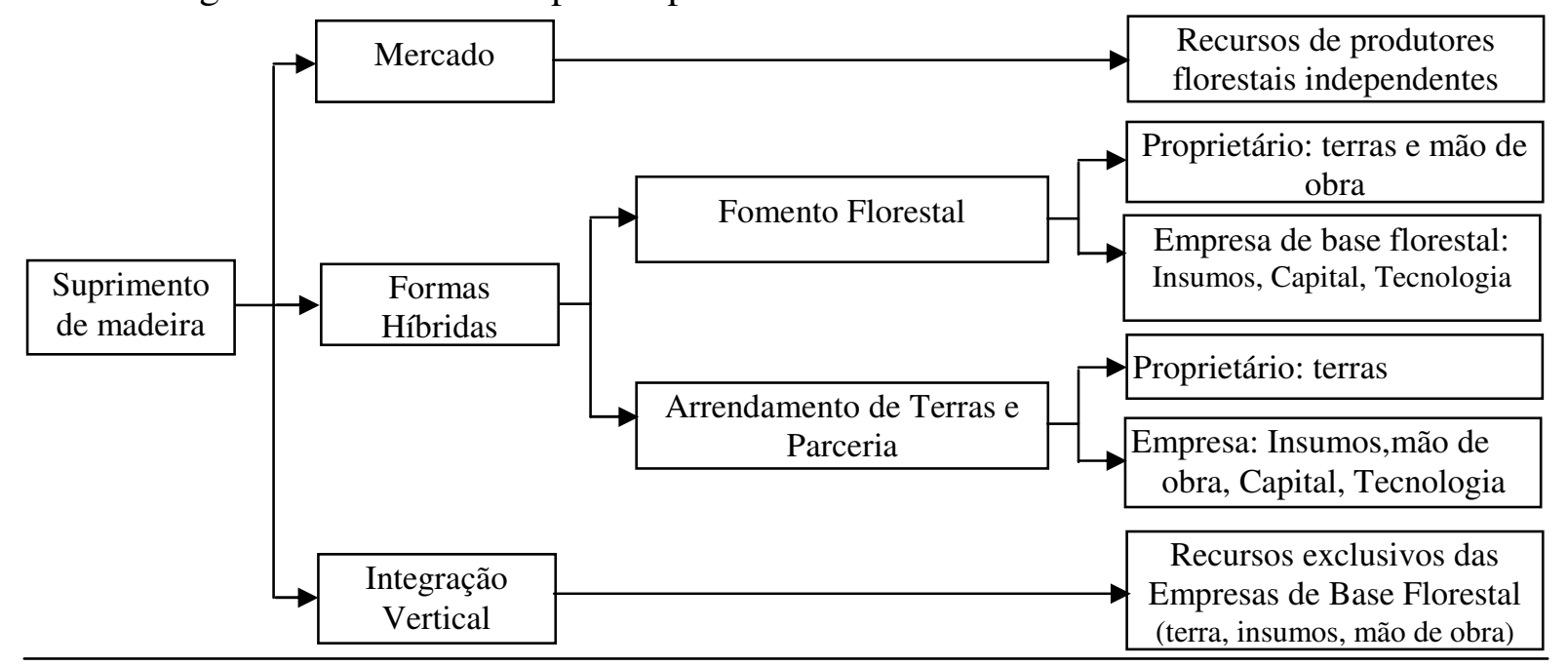

Fonte: os autores.

O mercado, como forma de suprimento de madeira é a alternativa predominante das empresas industriais de pequeno porte e de parte das empresas industriais de médio porte. Essa alternativa ainda não supre a demanda crescente da indústria de base florestal renovável. $\mathrm{O}$ cultivo florestal independente, destinado à produção de madeira bruta para fins comerciais REAd I Porto Alegre - Edição 72 - N 2 - maio/agosto 2012 - p. 494-520 
O fomento florestal como alternativa de suprimento de matéria-prima na indústria brasileira de celulose

ou industriais ainda está em formação, em virtude de sua retomada a partir de 2001. Por parte de produtores florestais independentes, o ciclo de produção florestal requer longo prazo para a maturação dos projetos de silvicultura, sendo este um fator de desestímulo, sobretudo para o pequeno produtor rural.

Das alternativas apresentadas, as formas híbridas merecem atenção, pois entre elas está o fomento florestal, objeto do presente estudo. As formas híbridas baseiam-se em relações contratuais de longo prazo e, com base em Rodriguez (2004), pode-se descrever as características de cada modalidade contratual.

O Arrendamento é a modalidade em que a empresa arrendatária assume a posse e a responsabilidade sobre a propriedade da terra de um terceiro, para o fim específico de florestamento e reflorestamento. Todos os custos de implantação e manutenção da floresta, de colheita, e da conservação da área arrendada são assumidos pela empresa. O proprietário do terreno é remunerado mediante pagamentos periódicos, por um preço preestabelecido, cuja base de definição varia entre as diferentes regiões.

A modalidade da Parceria Florestal possui quase todas as mesmas características do Arrendamento, distinguindo-se deste na forma de remuneração do proprietário. Nesta modalidade, o proprietário recebe como remuneração um percentual da produção, definido em cláusula contratual. O pagamento pode ser feito por meio de madeira, ou pela forma preferida, por um valor calculado com base nos preços praticados no mercado regional para a madeira em pé.

Por intermédio de contratos de fomento florestal, a empresa fomentadora fornece ao produtor fomentado as mudas, os insumos e a assistência técnica para a condução da floresta. O produtor assume a mão de obra para o plantio, a condução e a manutenção da floresta e o corte da madeira, podendo, algumas vezes, estas atividades serem financiadas pela empresa fomentadora, mediante adiantamentos financeiros periódicos. O produtor fomentado ainda assume o compromisso de venda de um dado percentual da produção de madeira à empresa fomentadora, pelos preços do mercado regional. Ao cumprir esta condição, o produtor é isentado pela empresa do pagamento das mudas e insumos fornecidos, caracterizando, assim, o incentivo à produção. A relação contratual de um programa florestal geralmente envolve elementos que não são contemplados nos contratos, sendo esta forma classificada por Barzel (2003) como um acordo. Para Barzel (2003), o termo "acordo" encerra uma transação inteira, enquanto o termo "contrato" encerra apenas parte de um acordo.

O termo fomento significa impulso ou estímulo mediante auxílio ou proteção, a uma região ou a um setor econômico, social, ou cultural, visando ao seu progresso ou REAd I Porto Alegre - Edição 72 - N 2 - maio/agosto 2012 - p. 494-520 
Augusto Fischer \& Décio Zylbersztajn

desenvolvimento. É utilizado genericamente para caracterizar as atividades de promoção do desenvolvimento rural, tanto na área floresta quanto na agropecuária. Tem sua aplicação mais frequente na área rural, quer na agricultura em geral, na pecuária, quer na área florestal.

Historicamente, o fomento tem contemplado os mais diversos segmentos da produção agrossilvipastoril. Conforme Kengen (2001), no Brasil, as atividades de fomento à agricultura têm uma longa tradição, particularmente aquelas voltadas para a produção de fumo, cana-deaçúcar, laranja, entre outras. Na área da pecuária, grandes empresas produtoras de aves e suínos também encontraram no fomento a parceria ideal para a expansão da produção.

Kengen (2001) também enfatiza que as funções de um programa de fomento são orientadas para o estímulo do desenvolvimento de determinada atividade, mediante um conjunto de incentivos à produção nessa atividade. Os resultados esperados com as atividades do fomento variam desde o abastecimento de matéria-prima às médias e grandes indústrias com abrangência regional, aos programas voltados para o abastecimento de determinada matéria-prima para um setor agroindustrial com abrangência nacional.

Um programa de fomento pode ser desenvolvido pela iniciativa pública, privada, ou conjunta, quando envolve ações públicas e privadas. Sob a iniciativa pública, geralmente caracteriza-se como um programa de extensão rural para incentivo a pequenos produtores. Nesse caso, inclui geralmente o repasse aos beneficiados, de recurso a fundo perdido.

A integração vertical é o arranjo organizacional predominante entre as empresas de médio e grande porte do setor de base florestal. A madeira para abastecer as plantas industriais dessas empresas é predominantemente produzida por elas próprias, em terrenos de suas propriedades ou arrendados de médios e grandes proprietários para o cultivo florestal. Este arranjo é mais frequentemente utilizado pelas empresas dos segmentos mais intensivos em capital, como o segmento de celulose e de aglomerados, e que utilizam somente madeira de florestas plantadas.

Para o presente estudo, as dimensões esperadas nos contratos de fomento são: os incentivos e as salvaguardas contraquebras contratuais. Os incentivos consistem no conjunto de benefícios incluídos nos contratos de fomento florestal, que estimulam a realização da relação contratual entre as partes, atraindo principalmente o interesse dos produtores rurais. Para este estudo, fornecimento de mudas e insumos para os cultivos florestais e a assistência técnica pelas empresas fomentadoras aos produtores florestais, constituem os incentivos. As salvaguardas compreendem os mecanismos de proteção da relação contratual, e se caracterizam como cláusulas que limitam ou desestimulam os comportamentos oportunistas ex post, assegurando maior estabilidade na manutenção dos contratos. Como salvaguarda, REAd I Porto Alegre - Edição 72 - N 2 - maio/agosto 2012 - p. 494-520 
O fomento florestal como alternativa de suprimento de matéria-prima na indústria brasileira de celulose

considera-se a fixação de multas pelo descumprimento de cláusulas estabelecidas no contrato. Nessa relação contratual, a empresa é detentora da tecnologia, e o proprietário rural detém a posse da floresta plantada. Sem cláusulas preventivas para as condições estabelecidas previamente, ambas as partes poderão incorrer em práticas oportunistas que resultarão em perdas de eficiência da relação contratual.

Ribeiro, Rodriguez e Zylbersztajn (2000) destacam que mudanças institucionais, notadamente o fim dos incentivos fiscais, elevaram os custos de produção (NORTH, 1990) das florestas plantadas, influenciando alterações da estrutura de governança do segmento de celulose. Tais mudanças influenciaram alterações da estrutura de governança dos demais segmentos industriais de base florestal, substituindo a integração vertical por arranjos contratuais de longo prazo. Rodriguez (2004) resgata a opinião de um empresário, ressaltando que “[...] a indústria não tem condições de dar conta da crescente demanda pela madeira de reflorestamento."

Entre os arranjos contratuais é comum a utilização conjunta das diversas formas de contratos, adotando ao mesmo tempo as modalidades de arrendamento e parceria florestal, paralelamente à integração vertical. A parceria florestal é desenvolvida em conjunto com o fomento florestal, daí ser muitas vezes confundida com este arranjo.

As explicações para as alterações nas estruturas de governança podem ser fornecidas pela Economia dos Custos de Transação (ECT) (WILLIAMSON, 1985, 1991a, 1996; NORTH, 1990; ZYLBERSZTAJN, 1995; BARZEL, 2003). Williamson (1991a, 1991b, 1996) propôs um modelo, estabelecendo uma forma analítica reduzida para comparação das diferentes formas organizacionais: de mercado, híbrida, e hierárquica. Para cada forma, define uma função de custo de governança utilizando como parâmetros os atributos da transação e elementos do ambiente institucional. O modelo apresentado na Figura 2 representa a relação entre os custos da estrutura de governança e a especificidade dos ativos, demonstrando que, à medida que aumenta a especificidade dos ativos, crescem as tendências pela adoção de formas hierárquicas de governança. 
Augusto Fischer \& Décio Zylbersztajn

Figura 2 - Relação dos Custos de Governança e Níveis de Especificidade dos Ativos

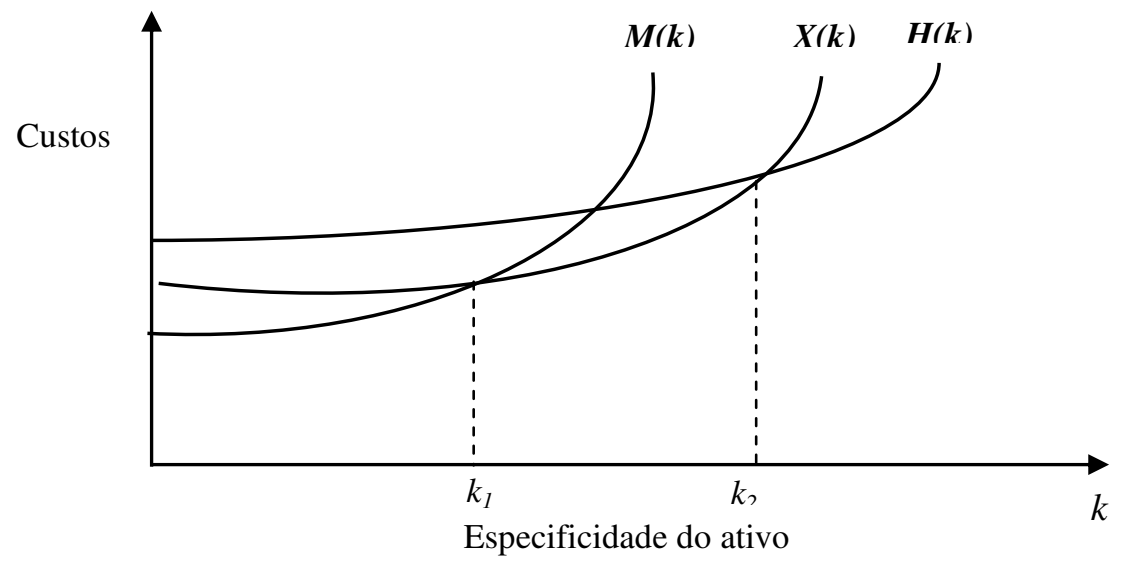

Fonte: WILLIAMSON (1996, p. 108).

Segundo Zylbersztajn (1995, p. 91), as três curvas - mercado $M(k)$; híbrida $X(k)$; e hierárquica $H(k)$ - definem uma fronteira de eficiência de custos mínimos associada a níveis crescentes de especificidade dos ativos $(\boldsymbol{k})$. Quando o grau de especificidade de ativos é baixo - até $\boldsymbol{k}_{\boldsymbol{l}}$ - o mercado é mais eficiente em termos de custos dos arranjos produtivos. Para os níveis de especificidade dos ativos situados a partir de $\boldsymbol{k}_{\boldsymbol{l}}$ até $\boldsymbol{k}_{2}$, os arranjos híbridos, onde a presença de relações contratuais está mais evidente, apresentam eficiência superior. Para níveis acima de $\boldsymbol{k}_{2}$ o arranjo mais eficiente em termos de custo é a forma hierárquica ou integração vertical.

As três curvas estão sujeitas aos deslocamentos, que resultam do crescimento de uma empresa e de mudanças nas condições do ambiente institucional e tecnológico (ZYLBERSZTAJN, 1995). Uma empresa pode iniciar sob uma estrutura de governança de mercado e, à medida que cresce, expandindo seu universo de influência, cresce também a complexidade organizacional, resultando no aumento dos seus ativos específicos. Essa condição passa a exigir a introdução de mecanismos de controle e de adaptabilidade, resultando no surgimento da governança híbrida. A partir desse estágio, novos níveis de crescimento da empresa levam à integração vertical de determinadas atividades, fazendo surgir a governança hierárquica.

Entretanto, nem sempre a integração é a melhor solução para a estrutura de governança. Zylbersztajn (1995) entende que novos estágios de crescimento da empresa, paralelamente ou não a mudanças no ambiente institucional e tecnológico, podem levá-la a mudar sua governança predominantemente hierárquica para a governança mista apoiada predominantemente pelas relações contratuais. As instituições podem gerar incertezas que 
O fomento florestal como alternativa de suprimento de matéria-prima na indústria brasileira de celulose

influenciam o desempenho econômico (NORTH, 1990) com o aumento dos custos de transação (WILLIAMSON, 1985).

Para Zylbersztajn (1995, p. 71), a análise das condições específicas nas quais a firma opera permitirá orientar uma melhor forma de organização da produção, que pode ser verticalizada, ou via mercado, ou, ainda, por intermédio de estruturas mistas entre mercados e internas, que caracterizam as inúmeras formas contratuais, como os contratos do fomento florestal. Os objetivos das estruturas de governança vão além da eficiência. Para Siffert Filho e Faveret Filho (1998), elas incorporam elementos de natureza estratégica, relacionados ao posicionamento da firma face aos seus rivais, razão pela qual, se deve considerar o ambiente concorrencial no qual se insere determinada firma. Tais elementos, associados a mudanças institucionais (NORTH, 1990), reforçam a consideração dos pressupostos comportamentais das transações, assumindo as possibilidades oportunistas, assim como as possibilidades de proteção contra o oportunismo de concorrentes.

A fronteira da eficiência explica os limites da integração vertical e, por essa razão, a forma mista de governança, como a estrutura predominante, nas empresas de grande porte na indústria de base florestal, fundamentando a opção pelo arrendamento de terras, pelas parcerias florestais e pelos programas de fomento florestal, por meio de contratos de longo prazo para o plantio de florestas destinadas ao suprimento de matéria-prima.

\section{METODOLOGIA}

Este trabalho foi desenvolvido por meio da abordagem qualitativa da pesquisa exploratória. A escolha dessa abordagem ocorre em virtude de que o contexto a estudar é pouco conhecido, e, em tal situação, segundo Yin (2005), a investigação mais adequada é pesquisa de natureza qualitativa de caráter exploratório.

Também foi utilizada a pesquisa descritiva, procurando mostrar as evidências entre as incertezas associadas ao ambiente institucional e os arranjos praticados pela indústria para assegurar o suprimento de madeira para processamento em suas fábricas. Essa opção foi feita com base em Gil (1995), que destaca com objetivo primordial da pesquisa descritiva, a descrição das características de determinada população ou fenômeno ou o estabelecimento de relações entre variáveis. Além do estudo exploratório e da pesquisa descritiva, foi realizado o estudo documental, objetivando analisar o ambiente institucional referente ao setor florestal no Brasil, e suas influências na indústria de celulose em particular. 
Augusto Fischer \& Décio Zylbersztajn

A coleta dos dados primários foi realizada por meio de questionário semiestruturado enviado aos responsáveis pelos programas de fomento florestal de empresas do segmento de celulose, através de correio eletrônico (e-mail). Escolheu-se essa forma de envio e recepção das respostas por se apresentar mais conveniente, prática e rápida. O período total da coleta se estendeu de julho a setembro de 2006.

Com base em estudos documentais, foram intencionalmente escolhidas aquelas empresas que desenvolvem programas de fomento florestal. Foram enviados questionários a 15 empresas produtoras de celulose que possuem programas de fomento florestal, das quais se obteve 11 respostas. As empresas que retornaram os questionários respondidos têm a seguinte distribuição: uma do Rio Grande do Sul; duas de Santa Catarina; uma do Paraná; uma do Espírito Santo; quatro de São Paulo; uma de Minas Gerais; uma da Bahia. As empresas respondentes possuem 42 unidades industriais e atuam em 13 estados no país. Contam com mais de 30 mil empregados diretos e mais de 30 mil terceiros. Também contam com aproximadamente oito mil participantes em programas de fomento florestal

Entre as empresas respondentes, oito são de capital nacional, duas têm participação de capital estrangeiro e uma é controlada por capital estrangeiro. Cinco empresas destinam sua produção exclusivamente ao mercado interno, e destas, três atendem à demanda de celulose de suas fábricas de papel e embalagens. As outras seis empresas, além do mercado interno, exportam sua produção, principalmente para Ásia, Europa e Estados Unidos; duas são líderes mundiais em celulose de fibra curta de eucalipto.

Foram consultadas 17,2\% das empresas produtoras de celulose no Brasil, cuja população é de 58\%. Em termos de participação de mercado, as empresas consultadas são responsáveis por mais de $76 \%$ da produção de celulose. O universo do segmento industrial de celulose e papel é constituído de 220 empresas, das quais, 23 empresas produzem somente pastas de alto rendimento (par) e 139 empresas produzem somente papel (BRACELPA, 2004).

Para o tratamento dos dados foi realizado agrupamento das seguintes categorias levantadas: a base de suprimento de madeira na indústria de celulose; a matriz de suprimento e os programas de fomento florestal; os incentivos e outras variáveis dos programas de fomento florestal. Em seguida fez-se a análise das categorias estabelecidas, buscando-se, inclusive, sua comparação com vistas a identificar as regularidades das características dos programas de fomento.

REAd I Porto Alegre - Edição 72 - N 2 - maio/agosto 2012 - p. 494-520 
O fomento florestal como alternativa de suprimento de matéria-prima na indústria brasileira de celulose

\section{RESULTADOS}

Fonseca et al. (2003, p. 6) destacam que o processo da produção de celulose é contínuo, com elevado investimento em capital fixo, conferindo pouca flexibilidade para ajustes a variações de demanda. A indústria brasileira de celulose baseia-se em madeira de reflorestamentos de eucalipto e pínus, e pelas características próprias de seu processo produtivo, tende a se estruturar de forma a reduzir sua dependência do mercado. O prazo de retorno de projetos florestais é longo, em razão de sua maturação, o que não o torna atraente para que um mercado de produção de madeira se desenvolva em níveis de garantir a demanda regular da indústria de celulose. Essa condição levou as empresas do segmento de celulose de grande porte, a desenvolverem as estratégias de suprimento de madeira baseadas na integração vertical ou na coordenação vertical por meio de contratos de longo prazo, com vistas a assegurar o suprimento de matéria-prima, reduzindo a incerteza do "tipo contingencial" (NEVES, 2000). Desenvolvem, assim, arranjos adequados aos limites da eficiência (WILLIAMSON, 1985).

A base de suprimentos da indústria de celulose é constituída pela integração vertical, pelas formas híbridas (arrendamentos, parcerias florestais e programas de fomento florestal), e pela via do mercado. A matriz de suprimento de madeira para processamento na indústria de celulose caracteriza-se conforme a Tabela 1 , indicando a tendência de relativa mudança da integração vertical para os programas de fomento e de mercado.

Tabela 1 - Matriz de suprimento de madeira na indústria de celulose (em \%)

\begin{tabular}{ccccr}
\hline Consulta & Terras próprias Arrendamento e Parcerias Programas de Fomento & Mercado \\
\hline Média em 2007 & 70,9 & 7,3 & 18,6 & 3,2 \\
Média Futura (2008 a 2010) & 68,9 & 7,3 & 19,4 & 4,4 \\
\hline
\end{tabular}

Fonte: os autores.

A integração vertical é a forma predominante para o suprimento de madeira nas onze empresas consultadas. Consiste no cultivo de florestas em terras de propriedade das empresas, com a alocação integral de recursos próprios, incluindo mudas e demais insumos. A maior parte dos demais recursos, como máquinas, equipamentos e mão de obra para plantios e manutenção, embora sendo predominantemente próprios, são usualmente contratados de terceiros prestadores de serviços. As características das empresas industriais do segmento de celulose, como o alto grau de investimentos, a longa maturação, e a presença de expressivas economias de escala, são as principais razões na utilização prioritária de recursos próprios na plantação de florestas para o suprimento de madeira. 
Augusto Fischer \& Décio Zylbersztajn

O estudo indica a tendência de pequena redução da integração vertical a montante na indústria de celulose e o aumento do arranjo híbrido, principalmente por meio do fomento florestal. Essa tendência reflete a preferência da indústria de celulose pelo aumento da eficiência do suprimento de matéria-prima, por intermédio dos arranjos contratuais, organizando sua governança de acordo com a fronteira de eficiência estudada pela economia dos custos de transação (WILLIAMSON, 1985; ZYLBERSZTAJN, 1995). A configuração e evolução da estrutura de governança é determinada pelas condições do ambiente institucional, pelas regras que orientam a concorrência, e pelo comportamento dos agentes (SIFFERT FILHO; FAVERET FILHO, 1998).

Em segundo plano desenvolvem-se os cultivos florestais por meio de programas de fomento florestal, por 10 das 11 empresas consultadas. Contudo, ponderando-se a participação do suprimento de madeira pela participação de mercado das empresas consultadas, os programas de fomento representam, atualmente, o segundo lugar na matriz de suprimento. Sua participação tende a crescer quando se consideram os programas atuais e as projeções de expansão dos programas de fomento apresentadas pelas empresas consultadas, conforme demonstra a Tabela 1.

Em terceiro plano, oito empresas consultadas desenvolvem as formas híbridas no cultivo de florestas para suprimento de madeira. Os arranjos híbridos compreendem as plantações florestais em terras arrendadas e as plantações florestais em parcerias com proprietários rurais. Entretanto, apurou-se que as parcerias florestais deverão ser estabilizadas, devendo ceder sua posição aos cultivos florestais mediante programas de fomento, particularmente entre as empresas consultadas.

A alternativa do mercado para suprimento de madeira está em quarto lugar na indústria de celulose. É utilizada por seis das 11 empresas consultadas; por quatro empresas constitui fonte suplementar e eventual de suprimento de madeira para processamento. As estimativas indicam que as compras de madeira de terceiros para processamento na indústria de celulose tendem a aumentar, apontando para, aproximadamente, 4,4\% na matriz de suprimento dentro de três anos.

O crescimento mais expressivo do mercado na matriz de suprimento é influenciado pelos programas de fomento florestal. As empresas consultadas que praticam o fomento florestal vendem excedentes de produção de madeira com bitolas superiores, e compram madeira com bitolas menores e mais adequadas ao processo industrial. Por outro lado, essa situação também reflete um dos objetivos implícitos dos programas de fomento florestal REAd I Porto Alegre - Edição 72 - Nº 2 - maio/agosto 2012 - p. 494-520 
O fomento florestal como alternativa de suprimento de matéria-prima na indústria brasileira de celulose

praticados por duas empresas consultadas. Para essas empresas, o fomento florestal destina-se a formar excedentes de produção de madeira que podem ser comercializados no mercado spot, contribuindo para a redução de pressões de demanda (RODRIGUEZ, 2004).

As restrições da legislação florestal e ambiental limitam o acesso e a disponibilidade eficiente das empresas a terras adequadas ao cultivo florestal. As preocupações em aumentar a utilização eficiente do recurso "terra" para cultivo florestal são algumas das razões que estimulam o desenvolvimento dos programas de fomento florestal. Entre os motivos que estimulam a substituição da integração vertical por esta modalidade destacam-se mudanças institucionais (ZYLBERSZTAJN, 1995), como: a desconcentração fundiária; o apoio ao cumprimento da legislação florestal; os incentivos ao uso múltiplo do solo; a menor pressão de ONGs contra monopólios de terra e latifúndios.

A função fundamental do fomento florestal é incentivar o cultivo florestal, visando ao aumento da base florestal para produção de madeira com fins comerciais (RODRIGUEZ, 2004). Além do suprimento de madeira para as empresas fomentadoras, objetiva substituir investimentos (WILLIAMSON, 1985; 1996) na aquisição de terras, reduzir custos, aumentar a disponibilidade e oferta de madeira, proporcionar fonte alternativa de renda e integrar as comunidades do entorno das fábricas de empresas fomentadoras. Um programa de fomento florestal constitui-se em um instrumento de valorização institucional (ZYLBERSZTAJN, 1995), refletindo, entre outras razões apontadas pelas empresas fomentadoras, os objetivos econômicos, sociais e ambientais.

Os objetivos econômicos do fomento florestal constituem a opção pela eficiência econômica, sem deixar de atender aos apelos ambientais da preservação da biodiversidade, e viabilizar a realização de funções sociais. Os principais motivos apontados para a adoção do fomento florestal são os seguintes: menores investimentos e redução de custos com a imobilização em terras; uso de terras ociosas para formação de florestas; incentivos ao uso múltiplo do solo; uso de mão de obra familiar em períodos de entressafra; aumento de produção de madeira em regiões vizinhas às instalações industriais; aumento da disponibilidade e oferta de madeira no mercado; redução da dependência do mercado no suprimento de madeira. Esses objetivos orientam-se para o aumento da base florestal com aumento da oferta de madeira, a redução dos custos de produção decorrentes da imobilização em terras pelas empresas (RODRIGUEZ, 2004; ZYLBERSZTAJN, 1995) e uma alternativa de renda para os produtores. 
Augusto Fischer \& Décio Zylbersztajn

Como objetivos sociais foram citados, pelos entrevistados, os seguintes: inclusão social de pequenos e médios produtores na área de abrangência das instalações industriais; distribuição e redistribuição de renda gerada pelas atividades florestais; apoio à permanência de pequenos produtores no meio rural; criação de nova alternativa de renda para produtores rurais.

Entre os objetivos ambientais, os entrevistados relatam que o fomento florestal: reduz as pressões sobre as florestas nativas; viabiliza a ocupação de áreas impróprias para as atividades agrícolas tradicionais e permite manter relativa diversidade da flora graças à ocupação descontínua dos espaços. $\mathrm{O}$ fomento florestal em pequenas e médias propriedades viabiliza relevante papel de natureza ambiental pela possibilidade de ocupação de pequenas áreas impróprias para as atividades agrícolas tradicionais, propiciando a manutenção da diversidade da flora graças à ocupação descontínua dos espaços. Por outro lado, algumas empresas fomentadoras permitem que parte da produção de madeira seja utilizada pelo produtor em sua propriedade, para lenha ou para outros fins.

No fomento florestal considera-se que a mão de obra é prestada pelos produtores rurais fomentados, ou por sua conta, embora algumas empresas a financiem. As principais variáveis presentes nos programas de fomento florestal das empresas fomentadoras são: o fornecimento de mudas e insumos (fertilizantes, formicidas, herbicidas), a assistência técnica e em frequentes condições, e os adiantamentos financeiros, detalhadas na Tabela 2. $\mathrm{O}$ fornecimento das mudas e de insumos constitui um dos incentivos básicos para a opção por parte dos pequenos produtores implantarem um projeto florestal.

Tabela 2 - Principais variáveis dos programas de fomento florestal.

\begin{tabular}{|c|c|c|c|c|c|c|}
\hline Empresa & Mudas & Insumos & $\begin{array}{c}\text { Adiantamento } \\
\text { Financeiro }\end{array}$ & $\begin{array}{l}\text { Assistência } \\
\text { Técnica }\end{array}$ & $\begin{array}{l}\text { Opção de } \\
\text { Compra }\end{array}$ & Modalidades de Fomento \\
\hline 01 & $\mathrm{D}$ & Fin. & Sim & Sim & Sim & 2 \\
\hline 02 & Ant. & Ant. & Sim & Sim & Sim & 2 \\
\hline 03 & D, Ant. & D, Ant. & Cf. mod. & Cf. mod. & Cf. mod. & 3 \\
\hline 04 & Ant & Ant & Não & Sim & Sim & 1 \\
\hline 05 & D. & $\begin{array}{l}\text { D, Ant. } \\
\text { Fin. }\end{array}$ & Cf. mod. & Sim & Sim & 2 \\
\hline 06 & D, Ant. & $\begin{array}{l}\text { D, Ant. } \\
\text { Fin. }\end{array}$ & Sim & Sim & Sim & 3 \\
\hline 07 & $\mathrm{D}$ & $3^{\circ}$ & Não & $3^{\circ}$ & Sim & 1 \\
\hline 08 & $\mathrm{D}$ & Não & Cf. mod. & Sim & Sim & 1 \\
\hline 09 & $\mathrm{D}$ & $\mathrm{D}$ & Não & Sim & Sim & 1 \\
\hline 10 & $\mathrm{D}$ & $\mathrm{D}$ & Cf. mod. & Sim & Sim & 3 \\
\hline 11 & $\mathrm{D}$ & Não & Não & Sim & Sim & 1 \\
\hline
\end{tabular}

Legenda: D = Doação; Ant. = Venda Antecipada; Fin. = Financiado; Cf. mod. = Conforme modalidade de fomento; $3^{\circ}=$ Fornecido por terceiros.

Fonte: os autores.

REAd I Porto Alegre - Edição 72 - N 2 - maio/agosto 2012 - p. 494-520 
$\mathrm{O}$ fomento florestal como alternativa de suprimento de matéria-prima na indústria brasileira de celulose

A maioria dos programas de fomento florestal possui como condição comum o fornecimento de mudas para reflorestamento, na forma de doação. A doação é caracterizada pelo fornecimento de mudas pelas empresas sem a exigência de reembolso ou contrapartida. O fornecimento das mudas como venda antecipada está presente nos programas de fomento de somente duas empresas, e em apenas uma modalidade de duas outras empresas que praticam mais de uma modalidade de fomento.

Caracteriza-se como venda antecipada, o fornecimento de mudas feito sob estritas condições contratuais e em conformidade com os empreendimentos florestais, objeto da relação de fomento, sendo o valor das mudas convertido em volume de madeira, cujo reembolso pelo produtor é feito futuramente, mediante a entrega de parte da madeira produzida à empresa, ou mediante dedução desse valor atualizado do montante correspondente à venda pelo produtor à empresa.

Os insumos - fertilizantes, formicidas, herbicidas - fornecidos aos produtores nos programas de fomento são disponibilizados nas condições similares aos fornecimentos de mudas, além do financiamento e do fornecimento por terceiros. Os resultados são os seguintes: duas empresas não tratam o fornecimento de insumos em seus programas de fomento; duas fazem a doação, somente; duas utilizam a antecipação das vendas, somente; uma faz doação e antecipação; duas fazem doação, antecipação e financiamento; uma faz o fornecimento através de terceiros. Além do fornecimento de mudas e insumos, os programas de fomento podem incluir a variável de adiantamento financeiro ou, simplesmente, financiamento, que no presente estudo é praticado por sete empresas.

Os financiamentos são concedidos por algumas empresas, na forma de adiantamentos reembolsáveis pelos produtores nas ocasiões das entregas de madeira. Em certos casos, as empresas fomentadoras são tão somente intermediárias avalistas dos financiamentos próprios, das linhas do Programa de Plantio Comercial e Recuperação de Florestas (Propflora) ou do Programa Nacional de Incentivo à Silvicultura e Sistemas Agroflorestais para a Agricultura Familiar (Pronaf Florestal). Nestes financiamentos concedidos pelos bancos repassadores, os recursos são liberados aos produtores mediante autorização das empresas fomentadoras.

A assistência técnica prestada aos produtores está presente na maioria das modalidades de fomento florestal. Para tanto, 10 empresas consultadas mantêm em seus quadros funcionais uma equipe técnica própria para as atividades de assistência ao programa de fomento. Uma empresa utiliza os serviços de assistência técnica de terceiros. Os serviços de assistência REAd I Porto Alegre - Edição 72 - N 2 - maio/agosto 2012 - p. 494-520 


\section{Augusto Fischer \& Décio Zylbersztajn}

técnica visam, principalmente, à produção de madeira destinada à empresa, sendo em geral prestados sem ônus aos produtores.

Todas as empresas fomentadoras assumem contratualmente a opção da compra da madeira produzida em todos os programas de fomento florestal, excetuando-se a modalidade de fomento de extensão praticada por uma das empresas. Os volumes de madeira produzida que os produtores estão obrigados em vender às empresas fomentadoras, ou a elas dar preferência de compra, variam de acordo com a empresa e a modalidade do fomento, sendo a maior frequência entre $95 \%$ e $97 \%$ do volume produzido.

Das empresas consultadas, seis desenvolvem os programas de fomento florestal em mais de uma modalidade. As demais empresas possuem uma modalidade apenas, principalmente porque estão na fase inicial de definição e implantação do programa. Entre os motivos pela diferenciação das modalidades de fomento, destacam-se os objetivos de alcançar diferentes grupos de interessados, e de acordo com o porte do produtor (pequeno, médio, ou grande), para incluir os mecanismos de incentivos adequados.

Além das variáveis demonstradas na Tabela 2, consideradas variáveis de incentivo, os programas de fomento também incluem mediante cláusulas contratuais, algumas dimensões de eficiência e salvaguarda, como a distância entre produtor e fábrica, a área mínima para o empreendimento florestal e a posse formal da terra sobre a qual deverá ser cultivada a floresta fomentada.

A distância é uma das variáveis consideradas nas definições de um programa de fomento, cuja frequência média da distância máxima é de 120 quilômetros. Contrariamente ao que se poderia supor, a distância das áreas fomentadas não é necessariamente menor que a distância de terras próprias, podendo ser até mesmo maior, pois essa diferença é compensável pelos custos menores de empreendimentos florestais fomentados em comparação aos empreendimentos florestais em terras próprias. Esta constatação é confirmada pelo modelo proposto por Williamson (1996) apresentado na Figura 2.

A área mínima para adesão ao programa de fomento ou à determinada modalidade do programa também influenciam na definição da distância. As áreas mínimas definidas pelas empresas fomentadoras para adesão ao programa variam, mas há maior predominância entre 5 hectares e 10 hectares. O limite mínimo quanto à área do empreendimento se justifica como um ponto de equilíbrio, em termos de custos de produção. Isto está fundamentado nas observações feitas pelos entrevistados, segundo os quais as áreas mínimas exigidas para adesão tendem a ser maiores quando a distância aceita é maior.

REAd I Porto Alegre - Edição 72 - N 2 - maio/agosto 2012 - p. 494-520 
O fomento florestal como alternativa de suprimento de matéria-prima na indústria brasileira de celulose

A posse formal da terra é uma das condições fundamentais para a efetivação e formalização do programa de fomento. As empresas evitam trabalhar com proprietários que não possuam títulos legais de propriedade das terras; não firmam contratos com propriedades sem registro ou título de propriedade. O registro do imóvel, sobre o qual se pretende implantar a floresta fomentada, é elemento condicionante para a efetiva participação no programa de fomento, sobretudo quando o fomento envolve um programa de financiamento, como o Pronaf Florestal ou o Propflora. Essa medida é uma salvaguarda contra possíveis quebras contratuais (WILLIAMSON, 1985; 1996; ZYLBERSZTAJN, 1995).

As empresas fomentadoras incluem cláusulas nos contratos de fomento florestal que possibilitam, pelo menos, a garantia para reaver seus desembolsos em benefício do produtor fomentado, por meio de mudas, insumos, serviços técnicos e adiantamentos financeiros. Nesse sentido, são inseridas cláusulas próprias nos contratos de fomento florestal, ou utilizam-se outros instrumentos de garantia, como a Cédula de Produto Rural CPR (ZYLBERSZTAJN, 1995).

No presente estudo não foram identificados problemas nas relações contratuais dos programas de fomento florestal, mas há relatos de problemas de relacionamentos, inclusive de ruptura de contratos de fomento florestal. Pela avaliação dos fatos, com base em dados secundários, observou-se que estes problemas ocorreram em contratos que envolvem grandes áreas de terras, o que pode configurar um comportamento oportunista (ZYLBERSZTAJN, 1995), principalmente por parte do produtor.

\section{CONSIDERAÇÕES FINAIS}

O objetivo deste estudo foi identificar a participação dos programas de fomento florestal no suprimento de madeira às indústrias de celulose, e identificar os incentivos e demais variáveis constantes nos contratos dos mesmos programas.

A indústria de celulose, que tipicamente se caracteriza pela integração vertical a montante, produzindo a maior parte da madeira para processamento, vem substituindo essa característica pela coordenação vertical, por meio dos arranjos contratuais, desenvolvendo os ajustes às mudanças institucionais geradoras de incertezas que influenciam a performance econômica (NORTH, 1990). Assim, passou a desenvolver a substituição da integração pelo cultivo florestal em terras de terceiros por meio de contratos de arrendamento de terra ou por meio de contratos de parceria florestal. Nessas circunstâncias iniciou, ainda na década de 1970, o desenvolvimento dos programas de fomento florestal, cuja participação na matriz de REAd I Porto Alegre - Edição 72 - N 2 - maio/agosto 2012 - p. 494-520 
Augusto Fischer \& Décio Zylbersztajn

suprimento de madeira para processamento já ocupa a segunda posição, na qual vem se consolidando com o crescimento em que se encontra.

Os programas de fomento florestal contemplam um conjunto de incentivos ao desenvolvimento da atividade silvicultural (RODRIGUEZ, 2004), como o fornecimento, por doação ou adiantamento, de mudas e insumos, o adiantamento financeiro e a assistência técnica para implantação e manutenção de florestas de eucaliptos e pínus. Os contratos de fomento florestal possuem cláusulas de opção de compra da produção de madeira, proporcionando para o produtor fomentado a garantia de comercialização, e para a empresa fomentadora a segurança no suprimento de matéria-prima. Os contratos de fomento florestal desenvolvidos pela indústria de celulose têm como referências relações mais amplas, nem sempre identificadas formalmente, sendo essa característica contratual definida por Mcneil (apud, WILLIAMSON, 1985), como uma mini-sociedade. O conjunto de variáveis e atributos presentes nas relações contratuais do fomento florestal caracteriza as relações contratuais como acordos nos quais se inserem os instrumentos de contrato (BARZEL 2003).

O fomento florestal influencia o desenvolvimento das três dimensões da sustentabilidade: econômica, social e ambiental. Os benefícios econômicos do fomento florestal se expressam na geração de rendas aos produtores participantes, e contribuem na dinamização do desenvolvimento local, possibilitando o surgimento de novos arranjos produtivos, cujos resultados se estendem aos benefícios sociais.

Sob a ótica social pode ser considerada a geração de renda adicional aos produtores rurais de pequenas e médias propriedades, com a consequente fixação destes em suas terras, reduzindo, assim, as migrações para áreas urbanas. Em horizontes de prazos mais longos pode-se esperar o surgimento de arranjos produtivos relacionados à madeira.

Os benefícios ambientais proporcionados pelo fomento florestal são inegáveis, podendo-se destacar a redução das pressões sobre as florestas nativas e áreas de preservação permanente e a utilização mais eficiente de terras, com o cultivo florestal em áreas impróprias para a agricultura tradicional, ou marginais a elas. Constata-se que o controle dos desmatamentos de florestas nativas pode lograr maior efetividade mediante programas de incentivo aos pequenos e médios produtores rurais, para cultivo de florestas, desenvolvidos pelas empresas consumidoras de madeira, e mediados por mecanismos públicos de estímulo, como linhas de financiamento e serviços de assistência técnica aos produtores.

Este trabalho limitou-se ao estudo dos programas de fomento florestal desenvolvido por grandes empresas produtoras de celulose. Apesar de seus benefícios e suas vantagens, o REAd I Porto Alegre - Edição 72 - N 2 - maio/agosto 2012 - p. 494-520 
O fomento florestal como alternativa de suprimento de matéria-prima na indústria brasileira de celulose

fomento florestal encontra limitações para se expandir na maioria das empresas do setor de base florestal de pequeno e médio porte. Esse programa é desenvolvido por empresas de grande porte, tanto no segmento de celulose, quanto no segmento de painéis reconstituídos e de serrados, isto é, tipicamente por empresas intensivas em capital. O desenvolvimento de fomento florestal por empresas de pequeno e médio porte requer uma estruturação que possa contemplar, além da capacidade financeira, a capacidade gerencial, envolvendo necessariamente o associativismo, como formação de cooperativas de produtores de um lado e de consumidores fomentadores de outro.

O fomento florestal tem grandes possibilidades de crescimento, por incluir variáveis favoráveis aos interesses das empresas e dos produtores. Todavia, para que logre êxito, um programa de fomento florestal não pode ser estruturado somente como uma relação econômica bilateral entre empresa e produtor florestal. Sua estruturação deve contemplar uma relação trilateral entre os seguintes atores: os produtores florestais, geralmente pequenos e médios agricultores, como os interessados e beneficiários diretos do fomento; as empresas consumidoras de madeira que, mesmo com o ônus inicial pela alocação de recursos, terão consideráveis benefícios econômicos no médio e longo prazo, pela disponibilidade de matéria-prima, aumentando sua oferta; e a sociedade, a qual, por intermédio do governo, poderá ter algum ônus inicial com os programas de fomento, de forma direta ou indireta, mas que logrará benefícios sociais por meio da redução do êxodo rural e benefícios econômicos com a estabilidade da capacidade produtiva, geradora de divisas. Como exemplo, o ônus inicial da sociedade (ou governo) consistiria, eventualmente, na realização de serviços públicos, como estradas vicinais de acesso e outras benfeitorias.

Sugere-se a realização de estudos empíricos para avaliar eficiência da relação contratual dos programas de fomento florestal, visando ao aperfeiçoamento dos referidos programas. Também pode ser desenvolvido estudo para mensurar os benefícios sociais e ambientais proporcionáveis pelos arranjos de fomento florestal, contribuindo para orientar estratégias e ações mais amplas, que envolvam iniciativas privadas e públicas.

Finalmente, sugerem-se estudos exploratórios e descritivos em outros setores que desenvolvem relações de parceria produtiva entre produtores agropecuários e indústria de processamento e transformação de produtos agropecuários. 
Augusto Fischer \& Décio Zylbersztajn

\section{REFERÊNCIAS}

ANDREWS, Nirmal. Challenges for sustainable timber production and export for tropical countries: perspectives from the Asia-Pacific region. Paper prepared for the UNCTAD Expert Meeting on Environmental Requirements and International Trade: Geneva, 2-4 October 2002.

ASSOCIAÇÃO BRASILEIRA DA INDÚSTRIA DE MADEIRA PROCESSADA MECANICAMENTE - ABIMCI. Madeira Processada Mecanicamente: estudo setorial 2001. Curitiba, 2001. 27 p.

Estudo setorial 2003: Produtos de madeira sólida. Curitiba, 2003a. 67 p.

O setor florestal e o segmento de produtos de madeira sólida no Brasil.

Brasília-DF, Maio, 2003b.

BACHA, Carlos José Caetano; ANTONANGELO, Alessandro. O salto tecnológico da silvicultura brasileira. Revista Preços Agrícolas, Piracicaba: Escola Superior de Agricultura “Luiz de Queiroz", Universidade de São Paulo, n. 130, p. 29-30, 1997.

BARZEL, Yoram. (1997). Economic analysis of property rights. Cambridge : Cambridge University Press, 2.ed, 1997. 161p.

BRACELPA. Estatísticas Básicas. Disponível em: <http://www.bracelpa.org.br/>. Acesso em: 22 set. 2004.

BRASIL. Lei n. 4.771, de 15 de setembro de 1965. Institui o Novo Código Florestal Brasileiro. Diário Oficial da União, Brasília, DF. 16 set. 1965. Seção 1. p. 9529.

FAO. FAOSTAT data, 2004. Disponível em:

$<$ http://faostat.fao.org/faostat/collections?version=ext\&hasbulk=0\&subset=forestry $>$. Acesso em: 14 jul. 2004.

Food and Agriculture Organization of the United Nations. Global forest resource assessment 2000 (FRA 2000). Rome, 2001. Disponível em <http://www.fao.org/DOCREP/004/Y1997E/y1997e06.htm>. Acesso em 14 jul. 2004.

REAd I Porto Alegre - Edição 72 - N 2 - maio/agosto 2012 - p. 494-520 
$\mathrm{O}$ fomento florestal como alternativa de suprimento de matéria-prima na indústria brasileira de celulose

. States of the world's forests 2003. Rome. Disponível em:

<http://www.fao.org/DOCREP/005/Y7581E/Y7581E00.HTM>. Acesso em: 12 jul. 2004.

FONSECA, Maria da Graça Derengowski et al. Cadeia: Papel e Celulose. In: Estudo da competitividade de cadeias integradas no Brasil: impactos das zonas de livre comércio. Nota Técnica Final. Campinas: Unicamp-IE-NEIT, 2003. 86 p.

GIL, Antônio Carlos. Métodos e técnicas de pesquisa social. São Paulo: Atlas, 1995. 207 p.

IBGE. Produção da extração vegetal e da silvicultura. Comunicação Social. Disponível em: < http://www.ibge.gov.br/>. Acesso em: 27 nov. 2003.

Produção da extração vegetal e da silvicultura. Rio de Janeiro, v. 22, p. 1-47, 2007. Disponível em:

<http://www.ibge.gov.br/home/estatistica/economia/pevs/2007/pevs2007.pdf>. Acesso em: 27 nov. 2003.

KENGEN, S. A política florestal brasileira: uma perspectiva histórica. In: Trabalhos convidados IPEF, n. 34, p. 18-34, 2001. (Série técnica IPEF).

LEITE, Nelson Barboza. O setor florestal no Brasil. Seminário: A Questão Florestal e o Desenvolvimento. Rio de Janeiro, 8 a 9 de julho de 2003a.

<http://www.bndes.gov.br/conhecimento/publicacoes/catalogo/>. Acesso em: 26 jan. 2004.

. No Brasil, a floresta precisa crescer (Reportagem Bracelpa). O Papel, São Paulo, p. 67, abril. 2003b. Entrevista concedida a Fábio Saraiva.

NEVES, M. F. (Org.). Economia e gestão dos negócios agroalimentares: indústria de alimentos, indústria de insumos, produção agropecuária, distribuição. São Paulo: Pioneira, 2000 .

NORTH, Douglas. Institutions, institutional change and economic performance. New York : Cambridge University Press, 1990. 152pp. 
Augusto Fischer \& Décio Zylbersztajn

RIBEIRO, Ana Raquel B. M.; RODRIGUEZ, Luiz Carlos Estraviz; ZYLBERSZTAJN, Décio. Abastecimento de madeira para a produção de celulose: uma aplicação de economia dos custos de transação. Revista de Economia e Sociologia Rural, v. 38, n. 4, out./dez. 2000.

RODÉS, Leopold. Setor florestal no Brasil. Workshop: Biodiversidade - Perspectivas e Oportunidades Tecnológicas. Campinas, 29 de abril a 1 de maio de 1996. Disponível em: <http://www.bdt.fat.org.br/publicacoes/padct/bio/cap12/leosit.html>. Acesso em: 20 jan. 2004.

RODRIGUEZ, L. C. E. Levantamento das características contratuais das relações de fomento, arrendamento, parceria e compra de madeira de terceiros estabelecidas entre a indústria de base florestal e o produtor rural no estado de São Paulo. Piracicaba: Instituto de Pesquisas e Estudos Florestais, 2004. (Relatório de Pesquisa).

SIFFERT FILHO, Nelson Fontes; FAVERET FILHO, Paulo. O Sistema agroindustrial de carnes: competitividade e estruturas de governança. Revista do BNDES, Rio de Janeiro, v. 5, n. 10, p. 265-297, dez. 1998.

SOCIEDADE BRASILEIRA DE SILVICULTURA - SBS. Fatos e números do Brasil florestal. 2007. Disponível em:

<http://www.sbs.org.br/FatoseNumerosdoBrasilFlorestal.pdf>. Acesso em: 13 abr. 2009.

TOMASELLI, Ivan; SIQUEIRA, Joésio D. P. O apagão e o Brasil florestal 2020. Informativo STCP, Curitiba: STCP Engenharia de Projetos, n. 8. p. 4-9, 2004.

TUOTO, Marco. Apagão florestal e suas implicações. Disponível em: $<$ http://www.sbs.org.br/>. Acesso em: 26 nov. 2003.

URURAHY, José Carlos Cardoso. Brasil vive apagão florestal. Disponível em: $<$ http://www.sbs.org.br/>. Acesso em: 26 nov. 2003.

VIANA, Virgilio M. et al. Instrumentos para o manejo sustentável do setor florestal privado no Brasil: Uma análise das necessidades, desafios e oportunidades para o manejo de florestas naturais e plantações florestais de pequena escala. Série: Instruments for sustainable private sector forestry (Instrumentos para um Setor Florestal Privado Sustentável), International Institute for Environment and Development, Londres, 2002.91 p. 
$\mathrm{O}$ fomento florestal como alternativa de suprimento de matéria-prima na indústria brasileira de celulose

YIN, Robert K. Estudo de caso: planejamento e métodos. 3. ed. Porto Alegre: Bookman, 2005.

WILLIAMSON, Oliver E. The economic institutions of capitalism: firms, markets, relational contracting. New York: The Free Press, 1985. 450 p.

Comparative economic organization: the analysis of discrete structural alternatives. Administrative Science Quarterly, n. 36, p. 269-296, june 1991a.

Mercados y hierarquias: su análisis y sus implicaciones anti-trust. México: Fondo de Cultura, 1991b.

The mechanisms of governance. New York: Oxford University Press, 1996. 429 p.

ZYLBERSZTAJN, Décio. Estruturas de Governança e Coordenação do Agribusiness: Uma Aplicação da Nova Economia das Instituições. 1995. Tese (Doutorado de Livre Docência em Administração)-Universidade de São Paulo, São Paulo, 1995. 